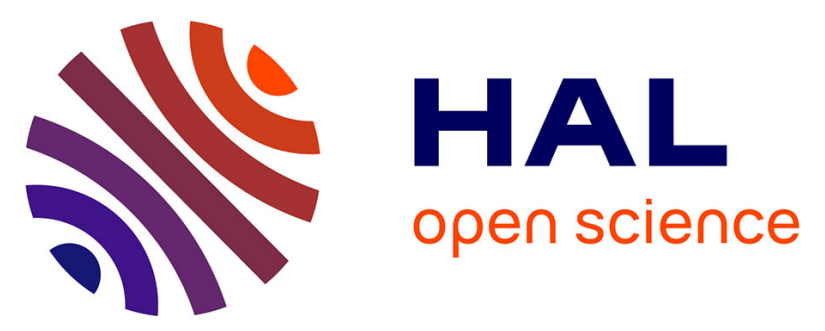

\title{
Measuring temperature of rotating cutting tools: Application to MQL drilling and dry milling of aerospace alloys
}

Gael Le Coz, M. Marinescu, A. Devillez, D. Dudzinski, Laurent Velnom

\section{To cite this version:}

Gael Le Coz, M. Marinescu, A. Devillez, D. Dudzinski, Laurent Velnom. Measuring temperature of rotating cutting tools: Application to MQL drilling and dry milling of aerospace alloys. Applied Thermal Engineering, 2012, 36, pp.434-441. 10.1016/j.applthermaleng.2011.10.060 . hal-03043922

\section{HAL Id: hal-03043922 \\ https://hal.univ-lorraine.fr/hal-03043922}

Submitted on 7 Dec 2020

HAL is a multi-disciplinary open access archive for the deposit and dissemination of scientific research documents, whether they are published or not. The documents may come from teaching and research institutions in France or abroad, or from public or private research centers.
L'archive ouverte pluridisciplinaire HAL, est destinée au dépôt et à la diffusion de documents scientifiques de niveau recherche, publiés ou non, émanant des établissements d'enseignement et de recherche français ou étrangers, des laboratoires publics ou privés.

\section{(1) (1) $\$$}

Distributed under a Creative Commons Attribution - NonCommercial - NoDerivatives 44.0 


\title{
Measuring temperature of rotating cutting tools ; application to MQL drilling and dry milling of aerospace alloys
}

\author{
G. Le Coz, M. Marinescu, A. Devillez, D. Dudzinski, L. Velnom
}

\begin{abstract}
After a brief bibliography on temperature measurement during drilling and milling, this paper proposes a new temperature measuring system for rotating cutting tools. The new system is composed firstly of a thermocouple integrated into the drill or into the mill and positioned as close as possible to the cutting face and near the cutting edge. To achieve the collect and the transmission of the temperature signals to the acquisition system, a data conditioning system and a wireless transmitter unit were incorporated into a special tool-holder. A Radio Frequency Antenna placed in the proximity of the tool holder completes the measuring system.

This system was used with success in studies for aeronautic industry. The first one consisted to optimize the cutting conditions during drilling of Ti6Al4V titanium alloy with a minimal quantity of lubricant (MQL). The objective of the second one was to test the thermal behavior of three different coated tools during dry milling of an aeronautic aluminum alloy. The paper presents some of these experimental results and demonstrates the efficiency of the proposed temperature measurement technique.
\end{abstract}

Keywords: Temperature measurement; Dry machining; MQL; Ti6Al4V; Aluminum alloy; coating. 


\section{Introduction.}

Several sources of heat appear during the metal cutting process; they are associated with the plastic deformation in the different shear zones, and the frictional dissipation energy generated at the tool-chip interface and at the interface between tool and workpiece. The generated temperatures have a significant influence on the friction conditions at the tool-chip and at the tool-workpiece interfaces and, as a consequence, on the level of cutting forces. The increase in the workpiece material temperature softens the material, and thereby decreases cutting forces and cutting energy to cause further shear. Temperature at the tool-chip contact affects the seizure and the sliding conditions at this interface [1,2].These conditions play an important role on the tool wear and then on the limitation of tool life. High temperatures at the tool-workpiece interface accelerate the flank wear mechanisms and promote plastic deformation on the machined surface. That leads to a significant thermal load of the subsurface which may induce phase transformation, generate surface alterations and produce high tensile residual stresses values which have a negative effect on fatigue life of the machined parts. When a minimal quantity of lubricant is used or when dry conditions are employed, all these effects are particularly critical and may be amplified. For these reasons, measuring and predicting temperature distributions in cutting tool are very important challenges. The temperature measurement is nevertheless really a severe problem for the following reasons: (a) heat generation regions in metal cutting are very narrow zones in the vicinity of the tool cutting edge; (b) the chip represents an obstacle to the cutting observation; (c) the tool-chip and tool-workpiece relative movements complicate the development of easy solutions.

This paper focuses on cutting tool temperature measurement techniques and is restricted to milling and drilling operations for which the main difficulty lies in the fact that the tool is rotating. Before presenting a new measurement technique and its application for determining cutting tool temperature during MQL (minimal quantity lubrication) drilling of titanium alloy and dry milling of aluminum alloy for aerospace industry, the measuring techniques used for these two operations are briefly reviewed.

\section{Temperature measurement in milling and drilling, a brief review.}

In metal cutting, most of the energy expended in plastic deformation and friction is converted into heat. It is possible to estimate the heat generated by measuring the temperature; however, this measurement is not generally so simple. Several techniques have been developed over 
time for the measurement of temperature in various manufacturing processes. They include principally thermocouples (the embedded thermocouple and the dynamic thermocouples or the chip-tool thermocouple), infrared thermography and optical radiation pyrometers. Two papers by Komanduri and Hou [3] and Davies et al. [4] reviewed an important number of measuring techniques. In the following a brief review on temperature measurement while drilling and milling is presented.

\subsection{Drilling.}

De Vries et al. [5, 6] were probably the first to determine drill temperature with ironconstantan embedded thermocouples and to study the effect of drill design variables on drill temperature responses. This kind of work continues today with Kalidas et al. [7] which inserted thermocouples at different locations in the workpiece, along the hole, to measure the maximum temperature rise. They used this temperature rise as a parameter to compare three different coatings in dry and wet drilling conditions.

Bagci and Ozcelik [8,9], studied the influence of spindle speed and feed rate on the drill temperature responses. They developed a new experimental setup using a thermocouple inserted through the oil hole of internal coolant carbide drill and fixed closer to the drill bit. To avoid, the problem of the tool rotation, the drill was put into a specially designed fixture and fixed on a dynamometer on the machine table, and the experimental workpieces were fixed on tool-holders. A similar experimental setup was used by $\mathrm{Li}$ and Shih [10] to study drilling of Ti6Al4V in wet and dry conditions. Wet experiments were possible because thermocouple wires in this study were routed up the drill body in hand ground grooves around the drill body surface to avoid the interference with the supply of cutting fluid.

Agapiou and Stephenson [11] used a vertical isolated wire inserted in the workpiece; every time the rotating cutting edge enters in contact with the wire, a hot thermoelectric junction is formed and the cutting edge temperature is then measured. In a technical brief, Bono and $\mathrm{Ni}$ [12] proposed a drill-foil thermocouple system. This system uses a layer of metallic foil embedded in the workpiece; when the drill contacts the foil, a thermoelectric junction is formed between the hot drill and the foil. Marinescu et al. employed a similar technique [13]. The greatest advantage of this method is that the drill makes continuous contact as it passes through the foil, this point of contact moves along the drill cutting edges and a temperature distribution may be obtained. 
The maximum tool temperature occurs at the maximum borehole depth and therefore it was measured at this point by Schulz et al. [14] and Dörr et al. [15]. They used infra-red thermographic cameras and a special fixture to measure the temperature when the drill passes through the workpiece bottom. In a more recent work, Pujana et al. [16] also used the infrared radiation thermometry to compare the classical and the ultrasonic-assisted drilling of Ti6Al4V. The temperature measurements have been done in two zones: the upper zone when the drill enters to the sample and the lower zone where the drill tip exits the sample.

Ueda et al. [17] proposed to use two-colour pyrometer with an optical fiber to measure the cutting edge temperature. The optical fiber was inserted in a small cylindrical hole made in the workpiece along the drilling direction, at different locations from the drill or hole axis. The drilling process was performed on a lathe; the optical fiber, inserted in the workpiece, was fixed to the bed of the lathe and the distance between the cutting edge and the incidence face of the fiber was maintained constant by using a specific set-up.

The thermal analysis of drilling is a key factor for the process and for the drill geometry optimization. The extreme cutting conditions in drilling have also as consequences difficult heat evacuation and then high temperatures generation. The drilling temperature is mainly affected by lubrication and cutting conditions and it is influenced by the drill design. The tool coating modifies the friction conditions and then the tool-chip and tool-workpiece heat transfers. The main difficulties are here the tool rotation and the fact that cutting zone is inside the workpiece making impossible the direct observation of the process.

\subsection{Milling.}

Little work was done in milling; the main difficulties in measuring cutting temperature during this process lie in the following facts: (a) tool is rotating and regularly entering and getting out of the workpiece; (b) the heat affected zone, between tool and workpiece, is moving on the workpiece surface; and (c) the chips may perturb the measurement. Thermocouples embedded in the workpiece and radiation thermometry techniques were previously mainly employed, they are here presented.

Kim et al [18] evaluated the temperature during high speed ball end milling of die steel using K-type thermocouples implanted into the workpiece at about $0.3 \mathrm{~mm}$ below the new generated surface. Wet, dry and air chilled cutting tests were realized and compared in terms of temperature and tool wear. $\mathrm{Ng}$ et al. [19] used the same embedded thermocouple technique to measure the cutting temperature when milling Inconel 718 with TiAlN coated tools. Dewes 
et al. [20] recorded tool/workpiece interface and chip temperatures during ball end milling of H13 hardened steel. The measurements were performed by using thermocouple and infrared camera techniques.

Lin [21] employed an infrared pyrometer (IR pyrometer) to determine the surface temperature history along the milling path. The IR pyrometer was arranged to follow the cutter at a distance of $17 \mathrm{~mm}$. Associated to the experimental measurement, they developed an inverse technique to predict the milling temperature and the heat flow. In the same way, Ming et al. [22] used IR pyrometer to measure surface temperature of a thin walled workpiece. The measured temperatures were used as an input for an inverse heat transfer model to calculate the heat flux and temperature distribution on the tool/chip interface.

Ueda et al. [23] investigated the temperature on the flank face of the cutting tool in high speed milling. The infrared rays radiated from the tool-workpiece interface were received and transmitted to a two-color pyrometer by using an optical fiber. The optical fiber was inserted into a fine drilled hole through the workpiece and fixed at the point where the distance between the surface to be machined and the tool flank face was $0.5 \mathrm{~mm}$. The temperature distribution along the cutting edge was also obtained by changing the setting position of the optical fiber.

Sato et al. [24], Ueda et al. [25] adapted the previous measurement technique to measure the tool face temperature in end milling. The tool insert was made by bonding a binderless CBN to a cemented carbide substrate. An optical fiber was introduced into the tool insert through a small hole drilled into the cemented carbide, up to the CBN tip. During the chip formation, the infrared rays radiated from the tool-chip interface through the CBN were received by a first optical fiber which ran inside the spindle. The radiation energy inside the first rotating fiber is then transmitted to a second static optical fiber, inside a fiber coupler used to connect the two fibers without contact. Finally, the infrared energy was focused and sent to the twocolor pyrometer. This experimental set-up was employed during milling (up and down milling) of carbon steel with two cutting speeds.

After this brief review, it may be concluded that choosing a temperature measurement technique is not easy. With Childs [26] and Ueda [23] it is possible to remind what are the important factors : temperature range, sensor robustness, temperature field disturbance by the sensor, sensitivity and signal noise ratio, response time; and the following criteria : easiness of calibration, availability, cost and size. In addition, for milling and drilling processes, the technique must be compatible with the tool rotation if it is the direct tool temperature 
measurement which is the objective; and finally for the cutting conditions optimization or for the best drill geometry definition and in an industrial context, the technique must be easy to use. In the next paragraph, such a technique is presented and used for the concerned machining operations and for the process optimization.

\section{Experimental procedure.}

\subsection{The proposed measurement technique.}

Direct tool temperature measurement during drilling and milling operations at high spindle rotation frequencies is the objective of the present work. The system proposed in this paper is based on a special tool-holder that assures a wire-less connection between a $\mathrm{K}$ type thermocouple inserted in the rotating tool and a data acquisition computer. Only the temperature is measured by this technique; axial force and torque are obtained separately from a 9265B Kistler dynamometer table. The proposed system was developed, calibrated and validated by the company Actarus.

The signal collected by the thermocouple embedded in the tool is transferred to the tool holder and sent to an amplifier by using a transmitter integrated in the tool holder and a Radio Frequency Antenna placed nearby the tool holder enabling a high speed data acquisition. Figure 1 presents a picture of the tool holder and the associated RF Antenna and data acquisition system.
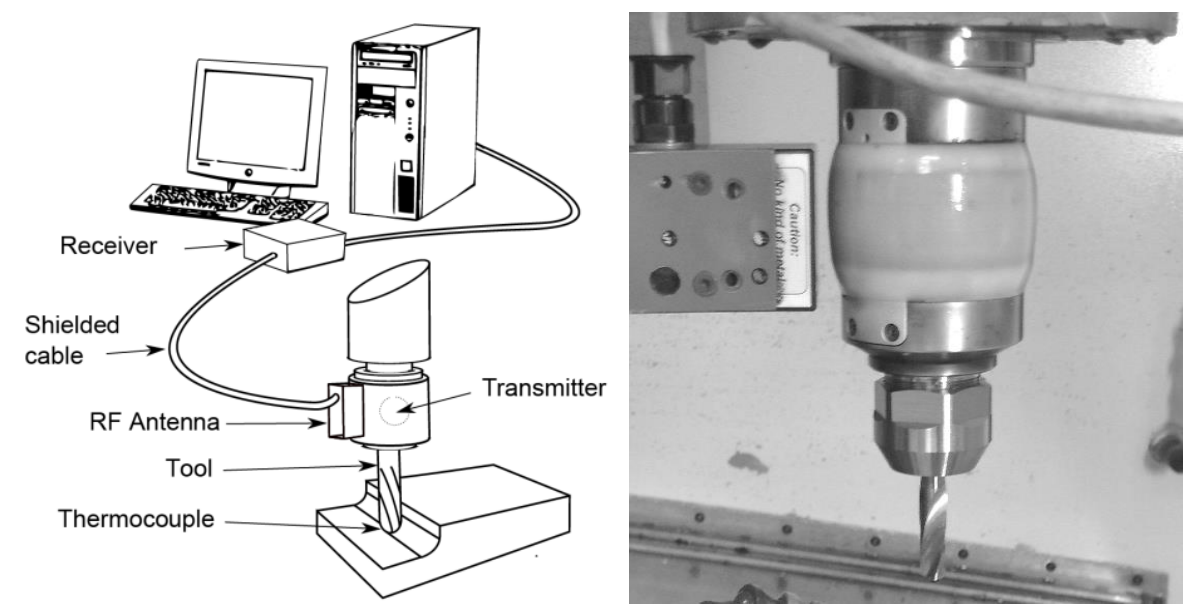

Figure 1. Tool holder, RF Antenna and data acquisition diagram.

The main characteristics of the tool-holder presented and used in this work are summarized in table 1 . One of the main advantage of the sensor is its design, that allows to perform high 
speed machining tests up to a maximum speed of $20000 \mathrm{rev} / \mathrm{min}$. In addition, this tool holder may be used both for drilling and milling operations, and internal lubrication is possible. Then, the influence of wet, dry or MQL conditions on cutting temperature may be studied.

$\begin{array}{ll}\text { Maximum rotation speed } & 20000 \mathrm{rot} / \mathrm{min} \\ \text { Acquisition frequency } & 1 \mathrm{KHz} \\ \text { Accuracy } & 1{ }^{\circ} \mathrm{C} \\ \text { Temperature measurement delay } & 150 \mu \mathrm{s} \\ \text { Coolant supplying holes } & \text { Yes } \\ \text { Shrink fit tool-holder } & \text { No } \\ \text { Applications } & \text { Milling/Drilling }\end{array}$

Table 1. Tool-holder characteristics.

A similar wireless unit was recently presented by Suprock et al. [27], incorporating a thermocouple and a strain gages in the tool to measure simultaneously tool temperature and torque for end milling. However, the milling tests were performed at low spindle speeds. In addition, with the proposed system, the temperature signal was only captured three times per second, and due to the thermocouple location in the tool body, the temperature sensor presented an important time delay of about 4 seconds.

In the following, the efficiency of the tool-holder is demonstrated during drilling and milling operations for the optimization of cutting conditions and to select a tool coating.

\subsection{MQL Drilling of Ti6Al4V alloy.}

Lightweight materials such as titanium alloys are used in modern aerospace structures due to their very good combination of metallurgical and physical properties. Titanium alloys advantages are: a high strength-to-weight ratio, a low density, an excellent corrosion and erosion resistance, and low modulus of elasticity, Ezugwu et al. [1], Machado et al. [2]. However, titanium alloys have been classified as difficult to machine due to their physical properties. The chemical reactivity of titanium alloys with tool materials and their consequent adhesion onto the cutting tool during machining leads to excessive chipping and/or premature tool failure and poor surface finish. Titanium alloys also have the tendency to form localized shear bands and can also maintain their high strength levels at elevated temperature in addition to their low modulus of elasticity and thermal conductivity. These characteristics cause high temperatures at the cutting interfaces during machining and result in higher tool wear rates. 
To reduce the waste, drilling titanium alloys with minimal quantity lubricant (MQL) technique is proposed. Small quantities of lubricant are mixed with compressed air for an external feeding via a nozzle or for internal feeding via spindle and tool. Internal feed systems with their ability to deliver the mixture very close to the drill-workpiece contact point may achieve very good results in terms of surface finish and tool life, Klocke and Eisenblätter [28]. The MQL is a suitable alternative for economically and environmentally compatible production. It combines the functionality of cooling lubrication with an extremely low consumption of lubricant and therefore it has the potential to close the gap between overflow lubrication and dry cutting, Dudzinski et al. [29]. However, the cooling effect obtained with MQL is limited, and consequently a significant rise in the temperature may be observed in the tool and in the workpiece during the drilling process. This temperature rise may activate the tool wear mechanisms, reduce the tool life and may affect the hole quality and generate residual stresses in the workpiece.

This paper presents results of an experimental study concerning drilling Ti6Al4V titanium alloy with a minimal quantity of lubricant (MQL drilling). The tool temperature rise during the drilling tests was recorded for various cutting conditions.

The drilling tests were performed on a Huron KX10 computed numerically controlled (CNC) vertical high speed machining centre $(24000 \mathrm{rev} / \mathrm{min}$ and $24 \mathrm{~kW})$. Plates of alpha-beta Ti6Al4V alloy were prepared; during the drilling tests they were mounted onto a Kistler piezoelectric dynamometer for force measurement. Holes of $20 \mathrm{~mm}$ depth were realized with $10 \mathrm{~mm}$ diameter drills. Uncoated drills were used in the experiments which characteristics are given by table 2 .
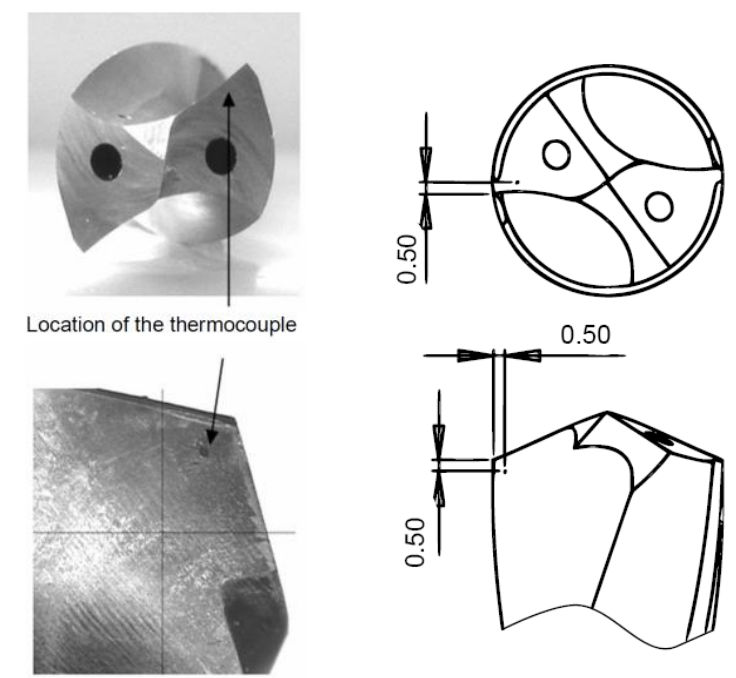

Figure 2. Drill bit used in the drilling tests and position of the thermocouple head ( $\mathrm{mm}$ ). 
Twist Drill diameter: $10 \mathrm{~mm}$; flute length: $43 \mathrm{~mm}$; point angle: $130^{\circ}$; helix angle: $15^{\circ}$; carbide type: K40

\section{Cutting Conditions}

Cutting speed $\mathrm{V}(\mathrm{m} / \mathrm{min})$

30 and 35

Feed rate $(\mathrm{mm} / \mathrm{rev})$

$0.1 ; 0.12 ; 0.14 ; 0.16$

Depth of drilling (mm)

Lubrication

20

Internal MQL

Table 2. Drill characteristics and cutting conditions.

The tool temperature was measured with a thermocouple inserted in the drill and the toolholder presented in the previous paragraph. The head of the thermocouple was positioned close to the corner of the drill and on the cutting face, figure 2. For the tests, two cutting speeds and feeds were retained. All the tests were performed three times to verify the repeatability, examples of such tests are given in the following paragraph 3.4. Axial force and torque were also measured by using the dynamometer table. These parameters were used to qualify and obtain the best cutting conditions with a particular attention on the maximum temperature reached during the tests.

\subsection{Dry milling of aerospace aluminum alloy AA 7075.}

Decreasing the costs of the cutting process and the associated reduction of environmental pollution by dry machining is the main key for the aerospace manufacturing industry to remain competitive. Dry milling of such an aluminum alloy was studied by Lahres et al. [30], they investigated the suitability of different commercial coatings. They have shown that specific coating systems or superhard diamond coatings exhibit a great potential for such operation. Different mechanisms can be the responsible of the tool wear in a cutting process. Usually, those mechanisms do not act separately in a cutting process, but they are combined. Adhesion wear is one of these mechanisms; it is the main tool wear phenomena when machining aluminum alloys. It is thermally activated and operates in a wider range of cutting temperatures. It leads to the formation of built-up edge and built-up-layer, which were investigated by Carrilero et al. [31] and Sanchez et al. [32].

Experimental results about dry milling of an aerospace aluminum alloy: $\mathrm{AlZnMgCu} 1.5$ (AA 7075) are presented in this paper. Adhesion wear appears to be the main tool wear mechanism during machining aluminum alloy; this wear mechanism is thermally activated. The tool temperature depends on tool coating, tool geometry and cutting conditions. Then, this 
temperature was measured for different coated tools, different tool geometries, and for given cutting conditions.

The milling tests were realized on a Roeders RP $600 \mathrm{CNC}$ (36 $000 \mathrm{rev} / \mathrm{min}$ and $17 \mathrm{~kW}$ ) high speed machining centre. This CNC machining centre is equipped with power controllers on each axis. Due to the specimen dimensions (blocks of $500 \mathrm{~mm}$ x $500 \mathrm{~mm}$ x $50 \mathrm{~mm}$ ), it was not possible to measure the cutting forces with a piezoelectric dynamometer table and only the consumed spindle powers were evaluated during the tests. Two different tool geometries were used during the tests. The angle of the helical grooves was the same for the two cutters; the discrepancy consists only on a modification of the rake angle. The helical grooves defining the rake faces of the two milling tools were obtained with two different grinding wheel profiles leading to two different rake angles. Three different coatings were tested, two nanostructured AlTiN and a diamond coatings. All the milling tests were performed in dry conditions. The tools characteristics and the cutting conditions are summarized in table 3 .

\begin{tabular}{|c|c|}
\hline Tools & Milling tool $\emptyset 16,2$ geometries \\
\hline Coating 1 & AlTiN, nano-structured coating $1,3 \mu \mathrm{m}$ thickness \\
\hline Coating 2 & AlTiN, nano-structured coating $2,3 \mu \mathrm{m}$ thickness \\
\hline Coating 3 & Diamond, $10 \mu \mathrm{m}$ thickness \\
\hline \multicolumn{2}{|l|}{ Cutting conditions } \\
\hline Cutting speed V(m/min $)$ & 700 \\
\hline Feed rate $(\mathrm{mm} /$ tooth $)$ & 0.2 \\
\hline Axial depth of cut (mm) & 4 \\
\hline Radial depth of cut (mm) & 8 \\
\hline Lubrication & Dry conditions \\
\hline
\end{tabular}

Table 3. Tool characteristics and cutting conditions. 

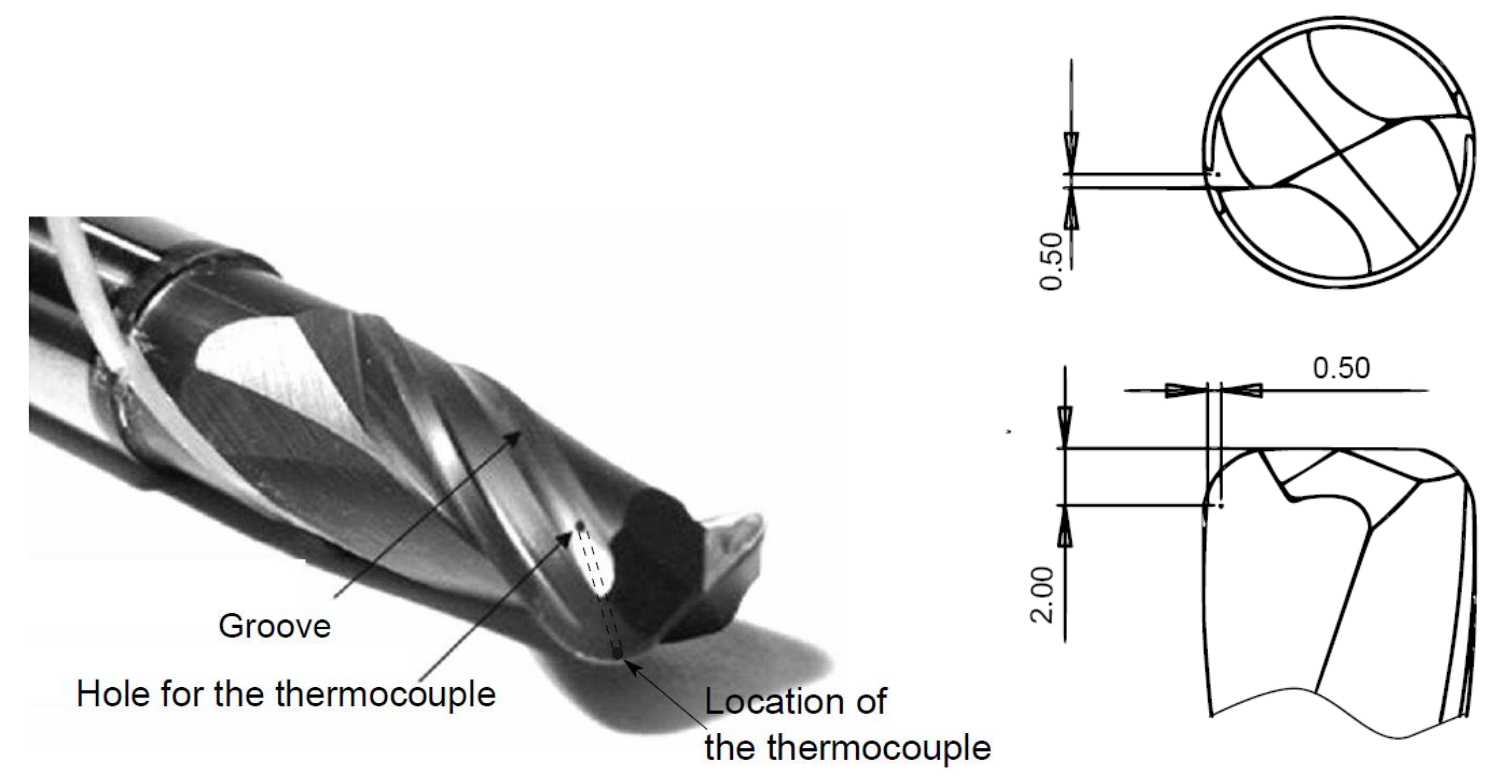

Figure 3. Tool used in the milling test and position of the thermocouple head (mm).

In the same way as in drilling, the tool temperature was measured by using an inserted thermocouple and the special tool-holder. The thermocouple and its connection wire were embedded in a special helical groove up to the clearance face of the end mill, and an electroerosion drilled hole allowed the location of the hot junction close to the cutting edge, see figure 3. All the tests were performed three times to verify the repeatability; examples of such tests are given in the following. 


\subsection{Repeatability tests.}

The feasibility and the repeatability were first investigated by measuring temperature for the two previous cutting processes giving low values of temperatures of about $150^{\circ} \mathrm{C}$ for aluminum milling and high values of about $600^{\circ} \mathrm{C}$ for titanium drilling. All the tests presented in this study were performed three times, such as the repeatability was verified all along this study. In this paragraph, only two series of tests are presented corresponding to the cutting conditions given in table 4 , they were chosen as repeatability tests.

\begin{tabular}{ccc}
\hline & drilling Ti6Al4V & milling AA 7075 \\
\hline Cutting Speed & $30 \mathrm{~m} / \mathrm{min}$ & $700 \mathrm{~m} / \mathrm{min}$ \\
Feed rate & $0.12 \mathrm{~mm} / \mathrm{rev}$ & $0.20 \mathrm{~mm} /$ tooth \\
\hline
\end{tabular}

Table 4. Cutting conditions for repeatability tests.

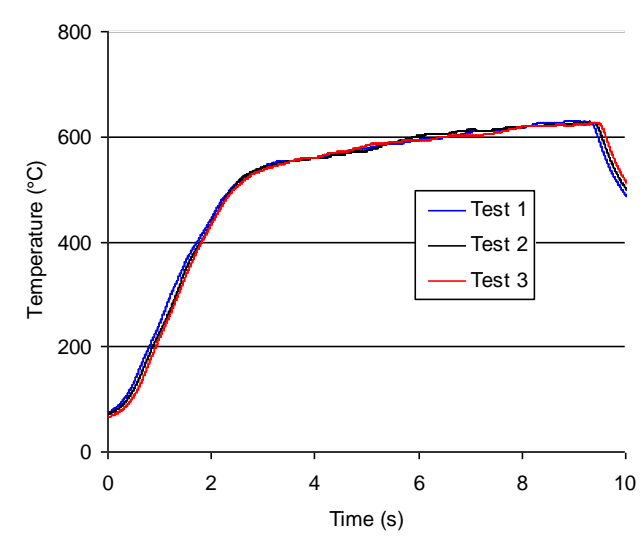

(a) drilling Ti6Al4V

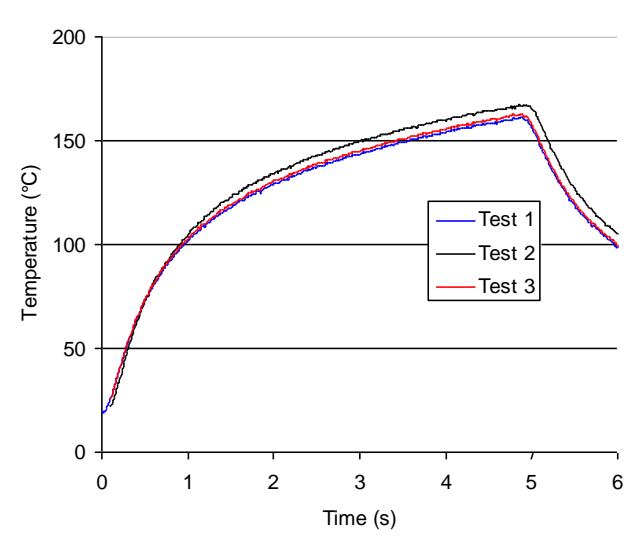

(b) milling aluminum alloy

Figure 4. Repeatability tests

Figure 3 gives the two series of temperature signals. The sampling frequency was chosen equal to $500 \mathrm{~Hz}$ giving an accurate temperature rising during the cutting tests. During the milling tests, the attained temperature was of about $160^{\circ} \mathrm{C}$ for a cutting length of $500 \mathrm{~mm}$. During the drilling tests, the maximum temperature was about $620^{\circ} \mathrm{C}$ for a hole depth of 20 $\mathrm{mm}$. The discrepancy between these two levels may be first explained by the fact that heating generated during the cutting process is not easily evacuated in a drilling operation. In 
addition, the thermo-mechanical properties of the titanium alloy (high flow stress and low heat conductivity) lead to high temperature levels in the cutting zone.

During drilling, two different phases were observed. During the first one, the temperature rises rapidly up to $500^{\circ} \mathrm{C}$, this first stage corresponds to the drill point penetration. During the second one, the temperature rise is reduced, and it does not attain a stabilized value. This second stage corresponds to the hole drilling at diameter $10 \mathrm{~mm}$ with a depth of $20 \mathrm{~mm}$. The heat generation during this second stage is due to the cutting and the chip evacuation processes; more precisely it is produced during the chip formation where the main part of plastic energy is converted into heat; it is also produced by the friction between the chip and the rake faces of the drill and the friction in the margin zone between the drill and the wall of the hole.

During milling, the signal corresponds to the complete milling operation from the entry to the exit of the workpiece (500 mm length of cut). The temperature rise is more progressive; and it must be noted that a steady state was not reached.

The decreasing of the temperature on the figures 4 corresponds to the exit of the tool from the workpiece, at the end of the test.

Finally, it can be seen on these figures, that the measured temperature profiles are for the three repeated tests very similar. The dispersions of the measured temperature values are lower than $+/-0.5 \%$ in drilling and $+/-2 \%$ in milling. This remarkable repeatability of temperature measurement was verified for all the tests presented in this paper.

\section{Results and discussion.}

\subsection{MQL drilling of Ti6Al4V alloy.}

Drilling tests were performed using the cutting conditions presented in table 2. For each cutting test, the thrust, the torque and the temperature were measured. Torque and temperature values reported on figures 5 are the maximum values attained at the end of drilling tests. Drilling temperature varies from 590 to $640^{\circ} \mathrm{C}$, these values are much higher than those obtained by Zeilmann and Weingaertner [33] when drilling Ti6Al4V with MQL. The reason is that they measured the drilling temperature with thermocouples inserted in the workpiece at a distance of $0.2 \mathrm{~mm}$ from the wall of the hole, and it is evident that the temperature rise is greater in the drill than in the workpiece 

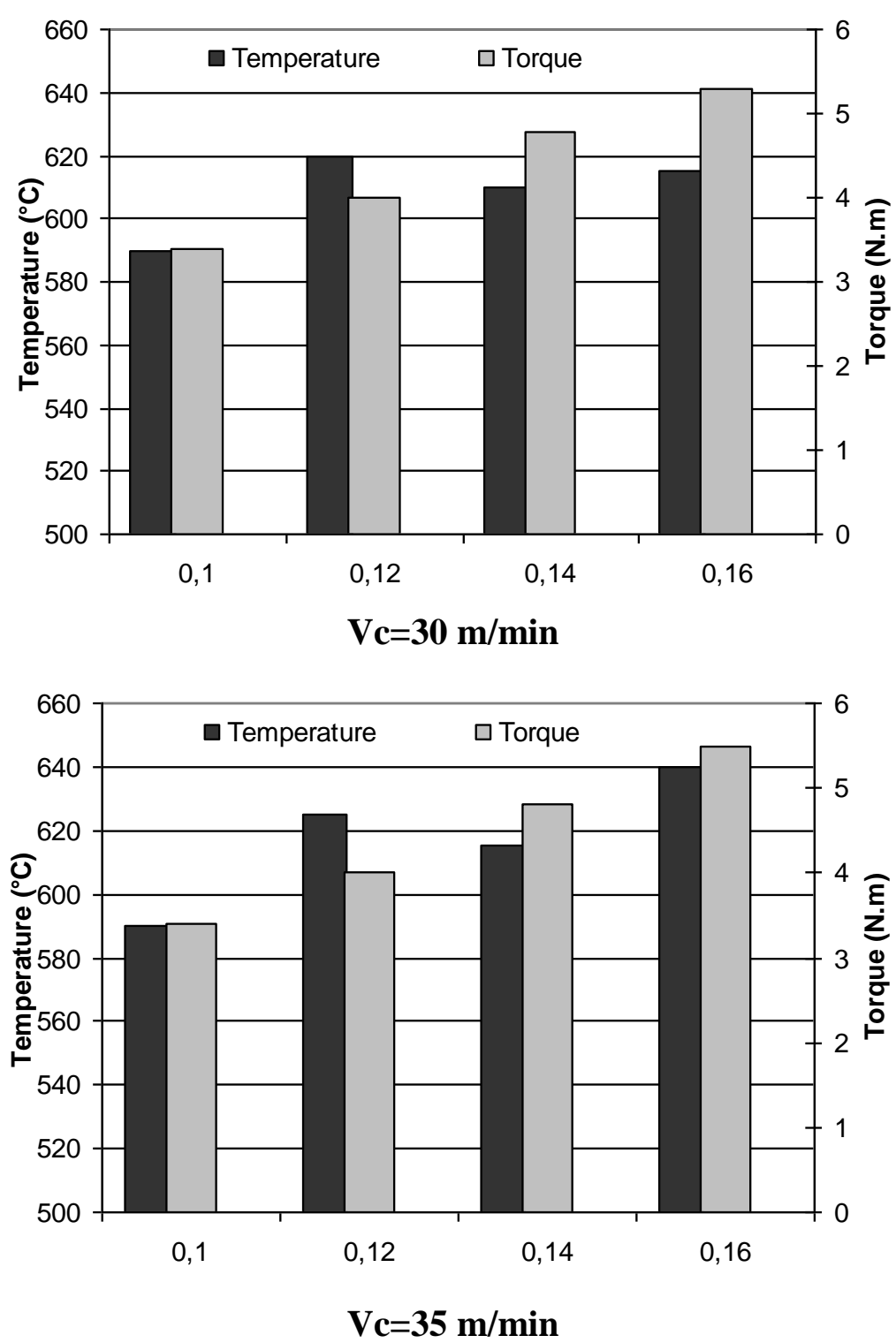

Figure 5. Temperature and torque when drilling Ti6Al4V alloy.

The torque increases with feed from 3.3 N.m to 5.4 N.m. This rise is simply explained by the increase of the chip thickness. A small modification of the cutting speed value has a little effect on the torque level. In opposite, the temperature evolution presents a singular point for the feed value of $0.12 \mathrm{~mm} / \mathrm{rev}$, for the two cutting speed values. It seems that this feed value generates worst conditions at the rake faces which induce higher temperature rise. The small increase of the cutting speed value from 30 to $35 \mathrm{~m} / \mathrm{min}$ leads to an increase of temperature, for all the feed values over $0.1 \mathrm{~mm} / \mathrm{rev}$, that demonstrates the sensitivity of the measurement system. 


\subsection{Dry milling of aeronautic aluminum alloy.}

The figures 6 present the measured maximum values of temperature and of consumed spindle power for the two mill geometries and the three coatings.

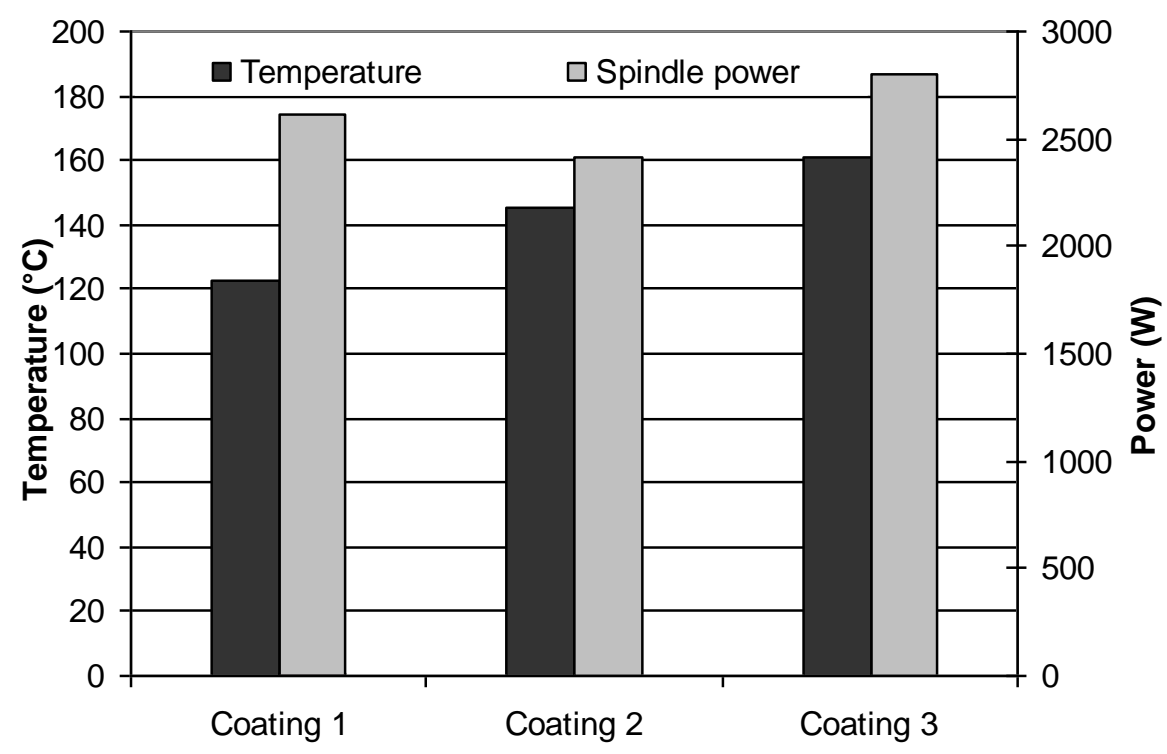

Geometry 1

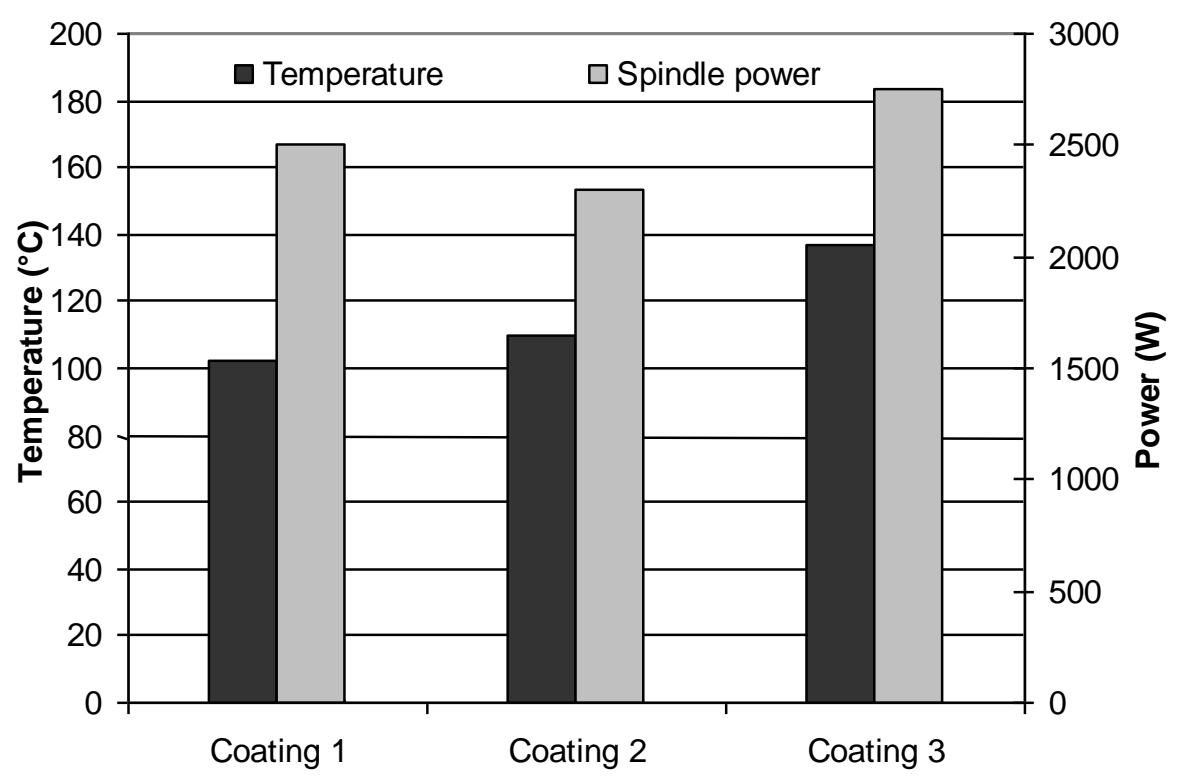

Geometry 2

Figure 6. Maximum temperature and spindle power for tool geometries 1 and 2.

As previously for the drilling tests, it can be noted that the measurement system is sensitive to the milling conditions. It is able to depict a significant difference on the tool temperature due to a change on tool coating or on tool geometry (rake angle). 
The geometry 2 corresponding to the smaller rake angle reduces the measured temperature of more than $20^{\circ} \mathrm{C}$, whatever the used coated tool. This geometry also limits the spindle power and as a consequence the cutting forces. In the same way, for the two geometries, the measured temperature is at is lower value when coating 1 is deposited on the tool. The two coatings ( 1 and 2 ) give the best behavior as thermal barrier and the best friction conditions at the tool chip interface. These coatings are two different versions of an AlTiN coating; measuring the tool temperature allows to display the discrepancy between these two closely coatings. The thickness of the diamond coating (Coating 3) was of about $10 \mu \mathrm{m}$ and it was of about $3 \mu \mathrm{m}$ for the AlTiN coatings. It is well known that increasing the coating thickness reduces the cutting edge acuity, leads to higher cutting forces and then to higher cutting temperatures and finally to least surface finish.

Measuring the tool temperature appears to be an interesting way to analyze the tool geometry and the coating effects. In this study, a tool geometry and tool coating were selected for additional tests concerning tool life and surface integrity. It can be noted that these two characteristics are, in their turn, greatly affected by the cutting temperature.

\section{Conclusions.}

In this paper, after a brief bibliography on temperature measurement during drilling and milling, a new temperature measuring system was proposed for rotating cutting tools. It was used with success during MQL drilling of Ti6Al4V titanium alloy to optimize the cutting conditions and during dry milling of aeronautical aluminum alloy to test the behavior of different tool geometries and coatings. The paper presents some results which correspond to parts of studies for aeronautic industry.

The proposed temperature measuring system corresponds first to a thermocouple integrated into the drill or into the mill and positioned as close as possible to the cutting face and near the cutting edge. To achieve the collect and the transmission of the temperature signals to the acquisition system, a data conditioning system and a wireless transmitter unit were incorporated into a special tool-holder. A Radio Frequency Antenna placed in the proximity of the tool holder completes the measuring system. The combination of these techniques corresponds to an original and innovative system for measuring the temperature of rotating cutting tools. 
With the proposed measurement technique, the following criteria were satisfied: (a) easy to use and to calibrate, it may be used in an industrial context; (b) it does not increase significantly the compliance of the cutting system; (c) the system is compatible with the existing tool types; (d) internal cooling (in drilling and milling) may be employed during the measurement; (e) the cost is limited in comparison with other system such as IR thermography camera.

In a machining process, tool temperature is one of the most important parameters in order to optimize the cutting conditions, limit tool wear and obtain acceptable surface integrity. Thus, the measurement of the temperature during machining is a significant goal and the system presented in this paper contributes to this objective.

It is demonstrated that the measurement system is very sensitive to any change on cutting conditions (cutting speed, feed rate, tool geometry, tool coating) and is able to measure lower temperature values (aluminum alloy milling) and high temperature values (titanium alloy drilling). All the tests were performed three times and the dispersion of the results is very low; in such a way the repeatability of the measurement is confirmed. Finally, the efficiency of the system was verified and it can be used for optimize a cutting process using rotating tools.

\section{Acknowledgments.}

The milling tests were carried out in the context of a research for EADS aeronautic industry supported by ADEME, the French Agency for Environment and Energy Management. The drilling tests were performed in a study for the tool manufacturer DIAGER Industrie. The authors would like to thank them for their help and their support.

\section{References.}

[1] E.O. Ezugwu, Z.M. Wang, Titanium alloys and their machinability - a review, Int J Material Processing Technology 68 (1997) 262-274.

[2] A.R. Machado, J. Wallbank, Machining of titanium and its alloys - a review, Proceedings of the Institution of Mechanical Engineers 204 (1990) 53-60. 
[3] R. Komanduri and ZB. Hou, A review of the experimental techniques for the measurement of heat and temperatures generated in some manufacturing processes and tribology, Tribology International (2001) 653-682.

[4] M.A. Davies, T. Ueda, R. M'Saoubi, B. Mullany, AL. Cooke, On the measurement of temperature in material removal processes, Annals of the CIRP 56 (2007) 581-604.

[5] M.F. DeVries, Mitchell, S.M. Wu, Measurement of drilling temperature by the garter spring thermocouple method, Microtecnic (1967) 583- 585.

[6] M.F. DeVries, S.M. Wu, Evaluation of the effects of drill design variables on drill temperature responses, Journal of Engineering for Industry (1970) 231-238.

[7] S. Kalidas, R.E. DeVor, S.G. Kapoor, Experimental investigation of the effect of drill coatings on hole quality under dry and wet drilling conditions, Surface and Coatings Technology 148 (2001) 117-128.

[8] E. Bagci, B. Ozcelik, Investigation of the effect of drilling conditions on the twist drill temperature during step-by-step and continuous dry drilling, Materials and Design 27 (2004) 446-454.

[9] B. Ozcelik, E. Bagci, Experimental and numerical studies on the determination of twist drill temperature in dry drilling: A new approach, Materials and Design 27 (2006) 920-927.

[10] R. Li, A.J. Shih, Spiral point drill temperature and stress in high-throughput drilling of titanium, International Journal of Machine Tools \& Manufacture 47 (2007) 2005-2017.

[11] J.S. Agapiou, DA. Stephenson, Analytical and experimental studies of drill temperatures, Journal of Engineering for Industry 116 (1994) 54-60.

[12] M. Bono, J. Ni, A method for measuring the temperature distribution along the cutting edges of a drill, Journal of Manufacturing Science 124 (2002) 921-923.

[13] M. Marinescu, Mesure et estimation de la température lors du perçage de l'alliage Ti6Al4V, Doctorat thesis, Metz University (2009).

[14] H. Schulz, J. Dörr, I.J. Rass, M. Schulze, T. Leyendecker, G. Erkens, Performance of oxide PVD-coatings in dry cutting operations, Surface and Coatings Technology 146-147 (2001) 480-485. 
[15] J. Dorr, Th. Mertens, G. Engering, M. Lahres, In-situ temperature measurement to determine the machining potential of different tool coatings, Surface and Coatings Technology 174-175 (2003) 389-392.

[16] J. Pujana, P.J. Arrazola, J.A. Villar, In-process high-speed photography applied to orthogonal turning, Journal of Materials Processing Technology 202 (2008) 475-485.

[17] T. Ueda, R. Nozaki, A. Hosokawa, Temperature Measurement of Cutting Edge in drilling - Effect of Oil Mist, Annals of the CIRP 56 (2007) 93-96.

[18] S.W. Kim, CM. Lee, D.W. Lee, J.S. Kim, Y.H. Jung, Evaluation of thermal characteristics in high-speed ball-end milling, Journal of Material Processing Technology 113 (2001) 406-409.

[19] E.G. Ng, DW. Lee, ARC. Sharman, R.C. Dewes, D.K. Aspinwall, High speed ball nose end milling of Inconel 718, Annals of the CIRP 49 (2000) 41-46.

[20] R.C. Dewes, E. Ng, K.S. Chua, P.G. Newton, D.K. Aspinwall, Temperature measurement when high speed machining hardened mould/die steel, Journal of Manufacturing Technology 92 (1999) 293-301.

[21] J. Lin, Inverse estimation of the tool work interface temperature in end milling. International Journal of Machine Tool and Manufacture 35 (1995) 751-760.

[22] C. Ming, S. Fanghong, W. Haili, Y. Renwei, Q. Zhenghong, Z. Shuquiao, Experimental research on the dynamic characteristics of the cutting temperature in the process of high speed milling, Journal of Material Processing Technology 138 (2003) 468-471.

[23] T. Ueda, A. Hosokawa, K. Oda, K. Yamada, Temperature on flank face of cutting tool in high speed milling, Annals of the CIRP 50 (2001) 37-40.

[24] M. Sato, T. Ueda, H. Tanaka, An experimental technique for the measurement of temperature on CBN tool face in end milling, International Journal of Machine Tools and Manufacture 47 (2007) 2071-2076.

[25] T. Ueda, M. Sato, A. Hosokawa, Development of infrared radiation pyrometer with optical fibers-two-color pyrometer with non-contact fiber coupler, CIRP Annals Manufacturing Technology 57 (2008) 69-72.

[26] P.R.N. Childs, Practical Temperature Measurement, Blutterworth Heinneman, Oxford. (2001) 
[27] C.A. Suprock, JS. Nichols, R.B. Jerard, B.K. Fussell, Calibration and implementation of a torque and temperature sensor integrated tooling system for end milling, CIRP conference on modeling of machining operations (2009) 403-409.

[28] F. Klocke, G. Eisenblätter, Dry Cutting, CIRP Annals - Manufacturing Technology 46 (1997) 519-526.

[29] D. Dudzinski, A. Devillez, A. Moufki, D. Larrouquère, V. Zerrouki, J. Vigneau, A review of developments towards dry and high speed machining of Inconel 718 alloy, International Journal of Machine Tools and Manufacture 44 (2004) 439-456.

[30] M. Lahres, P. Müller-Hummel, O. Doerfel, Applicability of different hard coatings in dry milling aluminium alloys, Surface and Coatings 91 (1997) 116-121.

[31] MS. Carrilero, R. Bienvenido, J.M. Sánchez, M. Álvarez, A. González, M. Marcos, A SEM and EDS insight into the BUL and BUE differences in the turning processes of AA2024 Al-Cu alloy, International Journal of Machine Tools and Manufacture 42 (2002) 215-220.

[32] J.M. Sanchez, E. Rubio, M. Alvarez, M.A. Sebastian, M. Marcos, Microstructural characterisation of material adhered over cutting tool in the dry machining of aerospace aluminium alloys, Journal of Materials Processing Technology164-165 (2005) 911-918.

[33] R.P. Zeilmann, W.L. Weingaertner, Analysis of temperature during drilling of TiAl4V with minimal quantity of lubricant, Journal of Materials Processing Technology 179 (2006) 124-127. 